\title{
Isolation and characterization of Arsenic tolerant fungal strains from contaminated sites around urban environment of Kolkata
}

\author{
Kaoushik K. Mukherjee, Dipanwita Das, A. C. Samal and S. C. Santra \\ Department of Environmental Science, University of Kalyani, Nadia, W.B., 741235, India.
}

\begin{abstract}
Today arsenic is causing an alarming global problem due to its toxicity and day by day this problem will amplify if necessary actions are not taken. In this paper we have isolated two arsenic resistant fungal strains (Aspergillus flavus and A. niger) from some polluted sites of Kolkata. These two strains are capable of removing 50\%-76 \% of arsenic from different arsenic enriched medium, simultaneously also tolerant to different other heavy metals $(\mathrm{Cd}, \mathrm{Pb}, \mathrm{Hg}, \mathrm{Zn}$ and $\mathrm{Cr})$. In near future these tolerant fungal species could be used in remediation of Arsenic and other metal pollution to some extent.
\end{abstract}

Key words: Arsenic, Aspergillus flavus \& A.niger, Bioremediation

\section{Introduction}

Development in terms of globalization and industrial expansion, heavy metal/metalloid pollution is attaining an alarming problem. Arsenic(As) pollution (a semi metallic element; metalloid) is one of the most concerned topic in recent years, as Arsenic is known to be a dangerous toxin that can lead to death when exposed to a large amounts. Arsenic, an ubiquitous metalloid found in groundwater due to its association with rocks, sediments and soils as well as industrial discharges and pesticide use which enters into the food chain through drinking water, crops and vegetables and causes different serious health problems.

Conventional physical and chemical methods for treating this harmful arsenic are inefficient, costly and not eco-friendly. So a global thrust was felt in searching of an alternative. Hence bioremediation is attaining an important procedure for abatement of metal pollution due to its low cost and high efficacy. Earlier Samal et al.[1] reported that among different algal strain blue green algal species Oscillatoria- Lyngbya mixed culture showed maximum efficiency in removing 64\% Arsenic (V) and 60\% Arsenic(III) after 21 days incubation from $0.1 \mathrm{mg} / \mathrm{l}$ arsenic (III) enriched medium. Similarly bacterial cultures also efficient in arsenic removal as reported by a group of researchers, they investigated $\mathrm{As}(\mathrm{V})$ reduction characteristics of two different bacteria named Pseudomonas stuzeri and Bacillus cereus and found 500ppb As(V) was completely reduced to As(III) by Bacillus cereus and Pseudomonas stutzeri in 114h and 120h respectively[2]. Among different microorganisms used in bioremediation fungi are considered as most effective species for metal removal from metal contaminated sites due to their survibility in higher concentration of metals. Evidence for internal absorption and the mechanism used by A. niger to detoxify environmental copper and zinc has been observed by earlier researchers [3]. Potential of filamentous fungi in bioremediation of heavy metals containing industrial effluents and waste waters has been increasingly reported from different parts of the world [4,5,6,7].

As far Kolkata is significantly less arsenic contaminated area, so we isolated fungal strains from some pollution stressed sites around peri urban areas of Kolkata. Our attempt was to screen out some Arsenic tolerant fungal strains which could be used in remediation of arsenic pollution to some extent in near future.

\subsection{Isolation of fungal strains:}

\section{Materials and Methods:}

Fungal strains were isolated from soils of five different sites of Kolkata; namely

(i) Waste dumping site of Dhapa areas of Kolkata;

(ii) Tannery waste dump sites along Eastern metropolitan bypass areas of Kolkata;

(iii) Contaminated site within the area of Central Bus terminus, Esplanade area, Kolkata ;

(iv) Waste dump sites within the premises of Calcutta medical college hospital, Kolkata.

The fungal strains were isolated through standard dilution plating methods [8] in Czapec-Dox(CD) agar media. Identically Czapecdox medium was prepared (glucose $-2 \mathrm{gm}, \mathrm{NaNO}_{3}-2.5 \mathrm{gm}, \mathrm{KCl}-0.5 \mathrm{gm}, \mathrm{MgSO}_{4}, 7 \mathrm{H}_{2} \mathrm{O}-$ $0.5 \mathrm{gm}, \mathrm{FeSO}_{4}-0.5 \mathrm{gm}, \mathrm{ZnSO}_{4}, 7 \mathrm{H}_{2} \mathrm{O}-0.5 \mathrm{gm}, \mathrm{KH}_{2} \mathrm{PO}_{4}-1 \mathrm{gm}$ and agar powder $15 \mathrm{gms}$ per liter). (APHA, 1992)

The species were purified by streaking repeatedly on the same medium and were identified on basis of macroscopic (colony character, morphology, colour, texture, shape, diameter and appearance of colony) and microscopic (septation in mycelium, presence of specific reproductive structures, shape and structure of conidia and conidiospore etc) characteristic using fungal identification manuals $[9,10]$. 


\subsection{Growth optimization}

Isolated strains were grown in sterilized $\mathrm{CD}$ broth medium for establishment of the optimum temperature, $\mathrm{pH}$ that supports the exuberant growth of those species. The $\mathrm{pH}$ of the medium was adjusted using dilute $\mathrm{HCL}$ or $\mathrm{NaOH}$. The temperature ranges were varied from $20^{\circ} \mathrm{C}-40^{\circ} \mathrm{C}$, and $\mathrm{pH}$ was from 3 to 9 .

\subsection{Antibiotic sensitivity Assessment}

Antibiotic (antifungal) sensitivity of each metal tolerant fungal strains were measured using cup assay method [11]. The antibiotics used for this assay were Nystatin, Griseofulvin and Kanamycin.

\subsection{Arsenic and another heavy metal tolerance assessment:}

To explore the tolerance of the isolates to the As, each freshly prepared growth medium were amended with selected metal concentrations varies from $50 \mathrm{mgL}^{-1}$ to $5000 \mathrm{mgL}^{-1}$. After 5 days of incubation, the extent of colony growth (in diameter) were compared with the control one (i.e. growth of fungi in medium without metal). All the experiments were carried out in triplicate.

For other heavy metals $(\mathrm{Cd}, \mathrm{Pb}, \mathrm{Hg}, \mathrm{Cr}$ and $\mathrm{Zn})$ resistance of the fungal isolates were determined by conventional cup assay method[11]. Selected metal tolerant fungal strains were grown separately in CD medium supplemented with diverse concentration (sub-lethal to lethal) of each heavy metal separately. Then cups were poured with various other metallic solutions $(\mathrm{Cd}, \mathrm{Pb}, \mathrm{Hg}, \mathrm{Cr}$ and $\mathrm{Zn}$ ). For each test triplicates were made and incubated for 5days. Zone of inhibition of fungal growth around the cup was examined and measured in each case separately

\subsection{Arsenic Removal potential of isolated strains}

To study the arsenic removal capacity the selected fungal strains were grown in Czapec Dox broth $(25 \mathrm{ml})$ with Sodium arsenite $\left(\mathrm{NaAsO}_{3}\right)$ concentration 20,100 and $1000 \mathrm{ppm}$ for 3,6 and 9 days with continuous shaking incubation at $30^{\circ} \mathrm{C}$ and $\mathrm{pH}$ 7. Fungal biomass was harvested by filtration through $0.22 \mu$ Millipore filter and the residual arsenic concentration of the broth was measured by FI-HG-AAS (Perkin Elmer Analyst-400) following standard procedure. All results are represented as the mean of triplicates.

\section{Results and Discussion:}

Almost twenty different fungal strains were isolated from soil samples of four different sites of Kolkata. Two arsenic tolerant strains ASC1 and ASB3 (isolated from Dhapa soil) were more arsenic resistant than other eighteen species, so we have carried out all our experiments with these two strains. The strains were identified as Aspergillus flavus (ASC1) and A.niger (ASB3) considering their colony color, colony shape, conidiospore color etc.

With increase in $\mathrm{pH}$ from 3 to 7 the biomass yield was found to enhance in both cases (ASC1 and ASB3) being maximum at $\mathrm{pH} 7$, further increase in $\mathrm{pH}$ caused decrease in biomass. Similarly maximum mycelial weight were obtained at $30^{\circ} \mathrm{C}$ temperature in both cases (Table $1 \&$ Table-2).Temperature $30^{\circ} \mathrm{C}$ and $\mathrm{pH} 7$,both these physical condition showed maximum growth in terms of mycelial weight so all further experiments were carried out maintaining these growth conditions.

Table-1 Optimisation of pH for growth of two isolated fungi (in terms of mycelia weight) after 5days of incubation

\begin{tabular}{|c|l|l|l|l|}
\hline Strain Name & \multicolumn{3}{|c|}{ Mycelial weight(g) } & (Mean \pm SD) \\
\hline & pH 3 & pH 5 & pH 7 & pH 9 \\
\hline ASC1 (Aspergillus flavus) & $1.3 \pm 0.2$ & $1.57 \pm 0.3$ & $1.89 \pm 0.52$ & $1.26 \pm 0.63$ \\
\hline ASB3 (A.niger) & $1.5 \pm 0.78$ & $1.87 \pm 0.54$ & $2.1 \pm 0.21$ & $1.7 \pm 0.45$ \\
\hline
\end{tabular}

Table-2 Optimisation of temperature for growth of two isolated fungi(in terms of mycelia weight) after 5days of incubation

\begin{tabular}{|c|l|l|l|}
\hline Strain Name & \multicolumn{3}{|c|}{ Mycelial weight $(\mathrm{g})(\mathrm{Mean} \pm$ SD) } \\
\hline & Temp.20 ${ }^{\circ} \mathrm{C}$ & Temp.30 ${ }^{\circ} \mathrm{C}$ & Temp.40 $^{\circ} \mathrm{C}$ \\
\hline ASC1 (Aspergillus flavus) & $1.15 \pm 0.25$ & $1.95 \pm 0.45$ & $1.01 \pm 0.32$ \\
\hline ASB3 (A.niger) & $1.3 \pm 0.20$ & $\mathbf{2 . 0 1} \pm 0.35$ & $1.69 \pm 0.56$ \\
\hline
\end{tabular}

Three different antibiotics (Nystatin, Griseofulvin and Kanamycin) were used to evaluate the antibiotic sensitivity of those two strains. ASB3 is found to be more resistant towards Griseofulvin and Kanamycin than ASC1, while against Nystatin both the strains showed similar range of tolerance (Table 3). 
Table 3 Antibiotic sensitivity assessment of both isolated strains

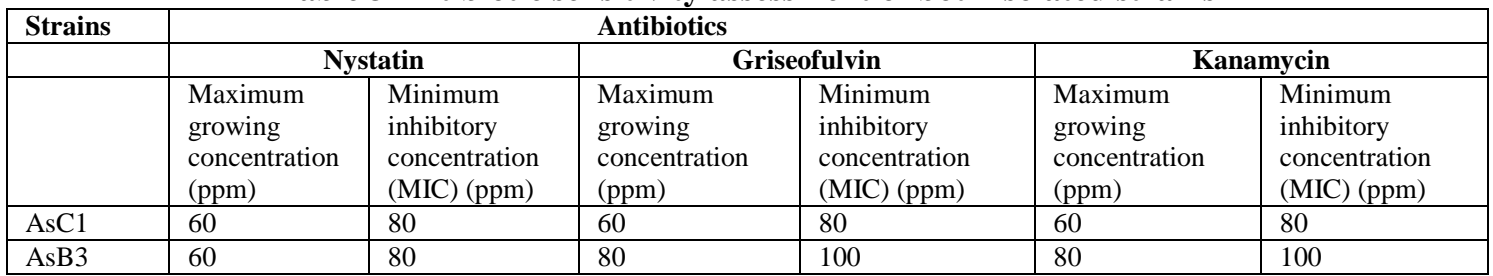

Our results depict that ASC1 is more arsenic tolerant than ASB3, as Minimum Inhibitory Concentration (MIC) of arsenic for ASC1 was estimated to be around 2000 ppm, where as for ASB3 it is 1200ppm. Similarly ASC1 is found to be resistant against $\mathrm{Cd}, \mathrm{Pb}$ and $\mathrm{Cr}$, while ASB3 is resistant for $\mathrm{Hg}$, and $\mathrm{Zn}$ ( Table 4)

Table-4 Metal tolerance assessment of isolated strains

\begin{tabular}{|l|l|l|l|l|l|l|}
\hline \multicolumn{1}{|c|}{ Strain Name } & \multicolumn{6}{c|}{ Minimum Inhibitory Concentration (MIC) in ppm } \\
\hline & As & Cd & Pb & Hg & Zn & Cr \\
\hline $\begin{array}{l}\text { ASC1 } \\
\text { (Aspergillus flavus) }\end{array}$ & 2000 & 500 & 700 & 55 & 650 & 1000 \\
\hline ASB3 (A. niger) & 1200 & 450 & 625 & 60 & 750 & 900 \\
\hline
\end{tabular}

Similar trend of results were obtained by Gautam et al.[12] where they reported maximum growth of fungi at neutral range of $\mathrm{pH}$. It is reported that temperature is considered as the most important growth factor for fungi [13]. Our results are in tune with the work of Santos \& Linardi [14] who have reported earlier that common incubation temperature for the growth of fungi such as A. niger, Fusarium sp., Penicillium sp. and Graphium sp. was taken as $30^{\circ} \mathrm{C}$. Actually this range of temperatures that encourage growth makes this isolate suitable for use in bioremediation in tropical climates.

Our results depicted that ASC1 is capable of removing more arsenic than ASB3 (Fig 1 \& Fig2). In case of both the strains maximum removal efficacy were obtained at $6^{\text {th }}$ day of incubation, with further increase in incubation time (i.e from $6^{\text {th }}$ day to $9^{\text {th }}$ day) a saturation was observed in removal efficacy for both of the cases(i.e. for both strains). Both the strains showed their maximum removal (70\%-76\%) efficiency when grown in $100 \mathrm{ppm}$ concentration of Arsenic. Further increase in metal concentration i.e from 100ppm to $1000 \mathrm{ppm}$ a significant decrease in removal percentage was noticed.

Bhar et al.[4] worked with Aspergillus, Rhizopus and Penicillium to show the rate of removal of As(III) and $\mathrm{As}(\mathrm{V})$ by above mentioned fungal strains and they found Penicillium with maximum removal efficiency and removal increases with increase of time interval which coincides with our results that with increasing incubation time $\left(3^{\text {rd }}\right.$ day to $6^{\text {th }}$ day) arsenic removal efficacies also enhanced upto a saturation time $\left(9^{\text {th }}\right.$ day).

Ridvan et al.[15] also worked with Penicillium purpurogenum to show bioadsorbtion capacity of heavy metal $\mathrm{Pb}, \mathrm{Cd}, \mathrm{As}$ and $\mathrm{Hg}$ and found metal accumulation $\mathrm{Pb}(\mathrm{II})>\mathrm{Cd}(\mathrm{II})>\mathrm{Hg}$ (II) $>\mathrm{As}$ (III)

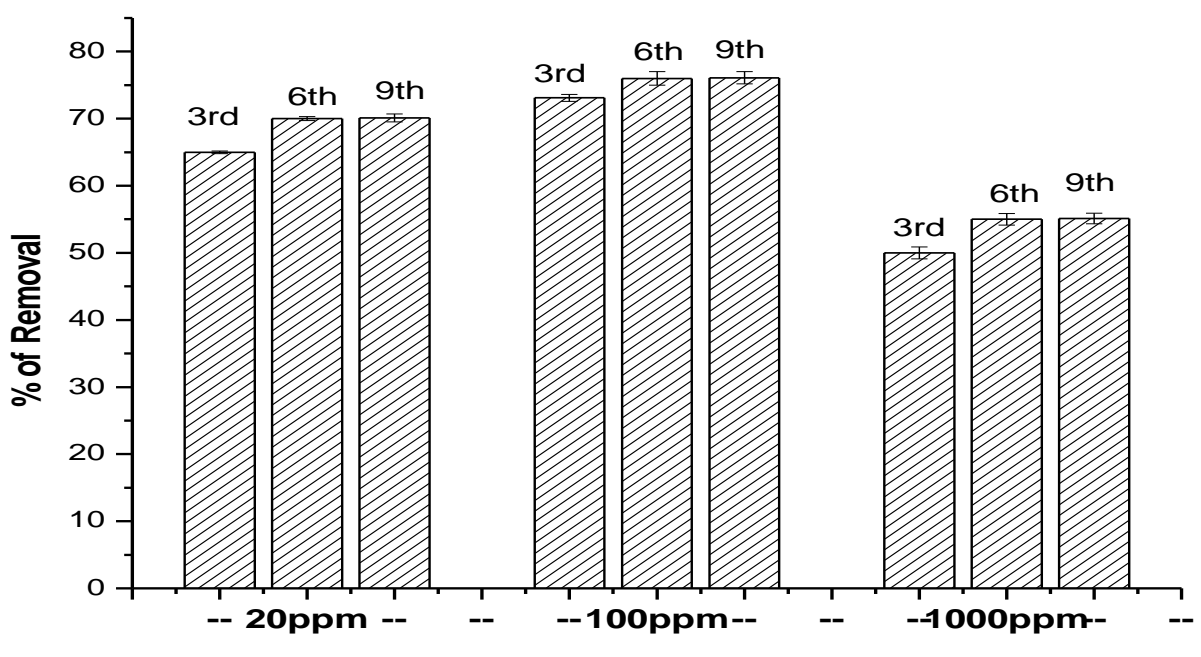

Fig-1 Arsenic removal (\%) of ASC1( A. flavus) from 20ppm,100ppm and 1000ppm Arsenic enriched media after $3^{\text {rd }}$ day, $6^{\text {th }}$ day and $9^{\text {th }}$ day of incubation period 


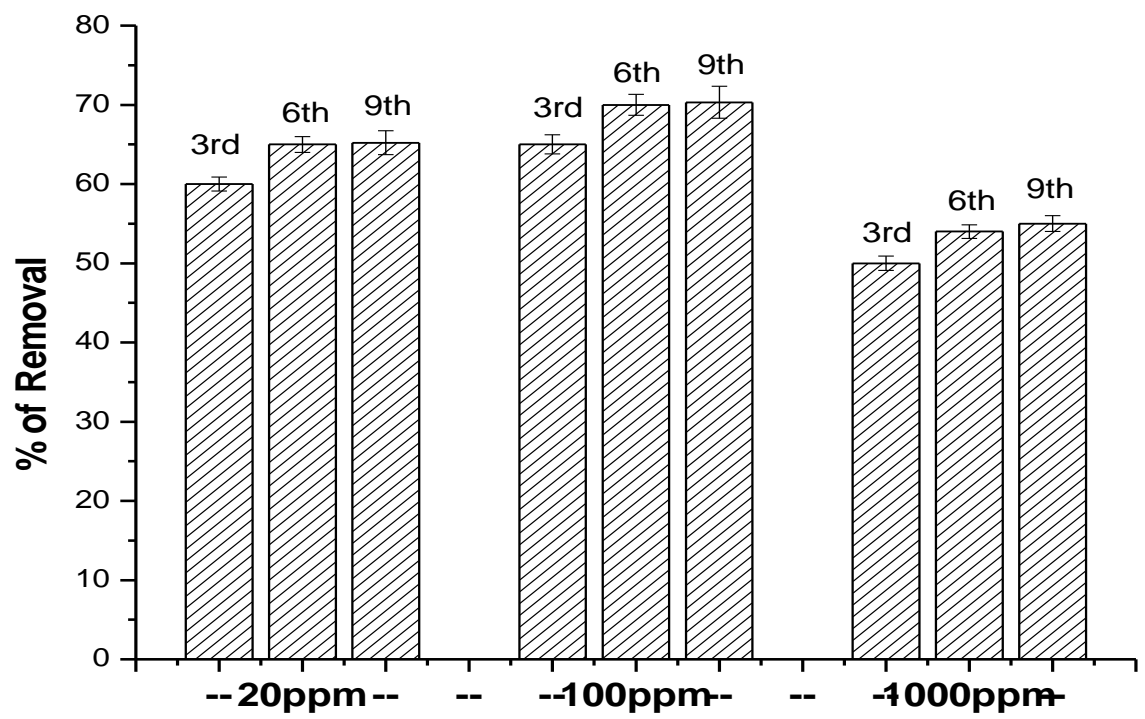

Fig-2 Arsenic removal (\%) of ASB3( A.niger) from 20ppm, 100ppm and 1000ppm Arsenic enriched media after $3^{\text {rd }}$ day, $6^{\text {th }}$ day and $9^{\text {th }}$ day of incubation period

Our results are in tune with the findings of a group of researchers, who reported arsenic removal potential of Aspergillus candidus and A. flavus respectively[16,17]. Similarly Srivastava et al.[18] detailed arsenic removal potential of Trichoderma and Aspergillus sp, isolated from arsenic contaminated sites of West Bengal. Almost ten species they identified which are tolerant upto $5000 \mathrm{mg} / \mathrm{L}$ of arsenic.

\section{Conclusion:}

These two isolated arsenic tolerant fungal strains (ASC1 and ASB3) could remove a significant amount of arsenic from different arsenic enriched media in laboratory condition. In near future these two fungal strains will be effective in arsenic removal planning from arsenic contaminated sites. The study revealed that a cost effective model of bioremediation of arsenic can be developed in a pilot scale.

\section{Acknowledgement:}

Authors are very much thankful to Dept. of Environmental Science, University of Kalyani, W.B. and DST-PURSE Programme, Govt. of India for carrying out this work.

\section{Reference:}

[1] A. C. Samal, G. Bhar, S. C. Santra, Biological process of arsenic removal using selected microalgae, Ind. J. Exp. Biol., 42, 2004, 522-528.

[2] J.P. Maity, S. Kar, J.H. Liu, J. S. Jean, C.Y. Chen, J. Bundschuh, S. C. Santra and C. C. Liu, The potential for reductive mobilization of arsenic [As(V) to As(III)] by OSBH2(Pseudomonas stutzeri) and OSBH5 (Bacillus cereus) in an oil contaminated site. Journal of Environmental Science and Health part A, 46:11, 2011, 1239-1246.

[3] M. S. Price, J. J. Classen, G. A. Payne, Aspergillus niger absorbs copper and zinc from swine wastewater. Biores. Tech. 77, 2001. 41-49.

[4] G. Bhar, A. C. Samal, S. C. Santra, An investigation on arsenic removal by soil fungal isolates. Sci \& Cult., 69(3), 2003, 157-158

[5] G. M. Gadd, Interactions of fungi with toxic metals. The New Phytology. 124, 1993. 25-60.

[6] J. L.Wang, C. Chen. Biosorption of heavy metals by Saccharomyces cerevisiae: a review. Biotechnology Advances. 24. 2006. 427451

[7] T. K. Pal, S. Bhattacharya, A. Basumajumdar. Cellular distribution of bioaccumulated toxic heavy metals in Aspergillus niger and Rhizopus arrhizus. International Journal of Pharma and Biosciences. VI (2), 2010. 1-6.

[8] R. C. Dubey, D. K. Maheswari. Practical Microbiology (First Edition. S. Chand and Company Ltd., New Delhi, India Reprint, 2005).

[9] K. H. Domsch, W. Gams, T.H. Anderson, Compendium of Soil Fungi (Academic Press, London, 1980).

[10] H. L. Barnett, B.B Hunter, Illustrated Genera of Imperfect Fungi (Burgess Publishing Company. Minneapolis, 1972).

[11] R. K. Dhar, J. Zheng, J. Rubenstone and A. V. Green, A rapid colorimetric for measuring arsenic concentrations in ground water. Analytical Chimica Acta. 526, 2004, 203-209.

[12] S. P. Gautam, P. S. Bundela, A. K. Pandey, M. K. Awasthi and S. Sarsaiya, Isolation, identification and cultural optimization of indigenous fungal isolates as a potential bioconversion agent of municipal solid waste, Annals of Environmental Science, 5, 2011, 23-34

[13] D. Delille, F. Coulan and E. Pelletier, Effects of temperature warming during a bioremediation study of natural and nutrientamended hydrocarbon-contaminated sub-Antarctic soils. Cold Reg. Sci. Technol. 40, 2004, 61-70.

[14] V. L. Santos \& V. R. Linardi, Biodegradation of phenol by a filamentous fungi isolated from industrial effluents-identification and degradation potential. Process. Biochem. 39, 2004, 1001-1006. 
[15] S. Ridvan, Biosorption of cadmium, lead, mercury and arsenic ions by the fungus Penicilium purpurogenum, Seperation Sc. and Technology, 38(9), 2003, 2039-2053.

[16] A.K. Vala, Tolerance and removal of arsenic by a facultative marine fungus Aspergillus candidus. Bioresour. Technol. 101(7), 2010, 2565-7.

[17] S. Maheswari and A. G. Murugesan, Removal of arsenic(III) from aqueous solutions using Aspergillus flavus isolated from arsenic contaminated sites. Ind. J. Chem. Technol., 18, 2011, 45-52.

[18] P. K. Srivastava, A. Vaish, S. Dwivedi, D .Chakrabarty, N. Singh, R. D. Tripathi, Biological removal of arsenic pollution by soil fungi. Sci Total Environ., 409(12), 2011, 2430-42. 